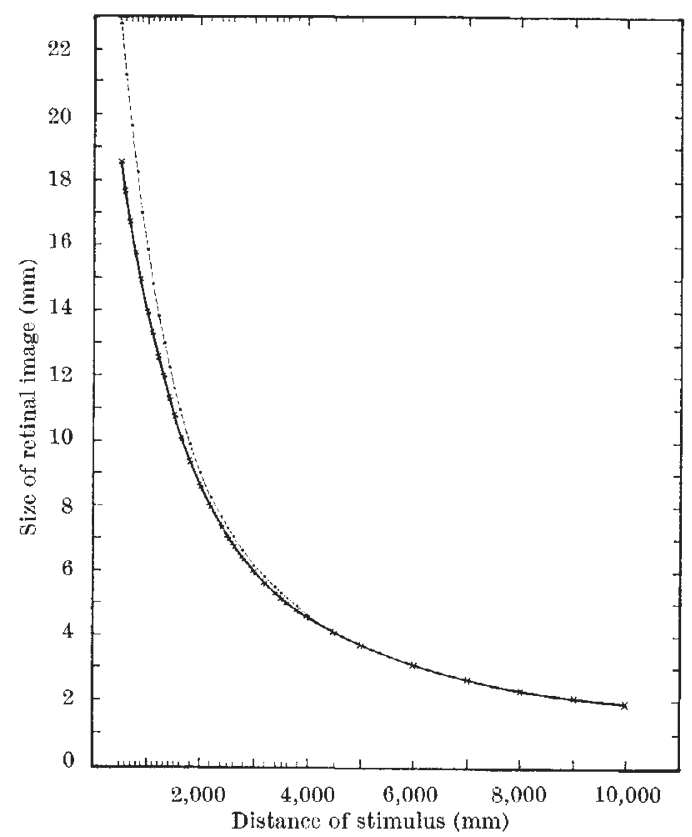
Fig. 3. Retinal image size and distance for an object $1,000 \mathrm{~mm}$ in

systems. It should be emphasized that the non-tinear function relating image-size with distance cannot account entirely for the appearance of spatial distortions. The calculations described above were confined to a static photo-optical system and size-constancy is far too great in magnitude to be described by either of the relationships illustrated in Fig. 3. Its appearance may be explained partially in these terms, however, because images tend to be larger in size with increasing distance than would be expected if they were related by an inverse function.

Geratd H. Fisher

Departmont of Psychology,

University of Newcastle upon Tyne.

Received October 14; revised November 28, 1968.

${ }^{1}$ Hochberg, J., Audio-Visual Communication Rev., 10, 22 (1962).

${ }^{2}$ Donders, 1. C., Anomalies of Aceommodation and Refraction (Publications onders, 1. C., Anomalies of Aceommodation and
of the New Sydenham Society, London, 1864).

${ }^{3}$ Helmholtz, H. von, Handbuch der Physioloyischen Optik, $\mathbf{3}$ (Voss, Hamburg and Loipzig, 1866) (trans. by Southall, J. P. C., Helmholtz's Treatise on Ahysioligical Optris) (Cover Publicaticns, NEW York, 1962).

“ Descartes, R., La Dioptrique, published with Discours de la Methode (Leyden, $1637)$.

${ }^{5}$ Gregory, R. I., Eye and Brain (Weidenfeld and Nicolson, London, 1966).

\section{Identification of Concealed Randomized Objects}

WE should like to make a few comments on two recent responses to a communication by J. G. P. et al. ${ }^{1}$.

Soveral of the questions raised by Farge ${ }^{2}$ quite correctly point to the lack of details amplifying the general statements to which the article was limited because of space restrictions. Readers who are interested in being more fully informed should read the full resoarch reports that have been appearing in the Journal of the American Society for Psychical Research beginning with the January 1968 issue. These articles contain details of the cardboard used in preparing materials for these exporiments.

The identifying numbers were written inside the covers. They were nover visible to the subject, and the experimenters saw them only at the end of each run after the subject's responses had been given and when the experimenters oxposod the numbers to themselves for recording purposes. But even though the numbers were not visible to the subject, we did not claim that the formation of response habits while the individual covers were exposed to the subject during sories 1,2 and 3 provided any evidence for ESP.

It is not rcasonable to assume that the subject could have been responding to differential placing of the covers within their jackets in those series in which the covers were concealed. The jackets were only wide enough to permit the covers to bo inserted without forcing, and they were always placed squarely against the lower ends of the jackets. Tho experimenter who randomized and concealed the covers was always completely screened from the sight of the subject and the experimenter who tested him. The experimenter working with the subject always gave the stack of prepared stimulus objects a random cut before they were used. Thus neither the experimenter who concealed the covers nor the experimenter who placed the stack in front of the subject had any sensory knowledge of the final order in which they were uscd during the run.

We were not concerned in our experiment with making distinctions between the subject's use of clairvoyance (direct extrasensory perception of a physical object), telepathy (extrasensory perception of the thoughts of another person) and other possible modes of ESP response, though wo think that clairvoyance is the most likely explanation of the results so far obtained.

Series of trials have already been performed both with empty covors and with empty jackets. In the former case, highly significant response preferences discriminating arrong the covers continued on the same pattern as when the cards were inside. Tests with the empty jackets wcre made after tho subject had developed response patterns for them, and these associative habits continued when the empty jackets were concealed inside 'Jiffy' bookmailing bags.

In his comments, Robertson ${ }^{3}$ gives no direct indication of having read the article itself, for he was reacting only to the heading "parapsychology" under which our report was classified. Scientific terminology introduced when it is first needed at an early stage of research, such as the word "atom" in physics, tends to be kept in use when the advance of scientific undorstanding makes the literal, original meaning inappropriate. We do not claim that "parapsychology" and "extrasensory perception" are ideal terms, but they have (like "atom") gained a currency in the literature that appears to justify their continued use as long as everyone really concerned understands what is meant. But we fear this may exclude the writer of that letter if we may judge from the parable he related. His statistical example has no relation to the research methods used by qualified investigators in parapsychology and it suggests that he has a totally erroneous conception of the evidence on which the case for ESP rests. Parapsychological experiments are not concerned with the occurrence of something improbable such as particular results from tossing coins or drawing cards. They are instead concerned with the improbability of correspondenees between statements made about such events in the absence of normal knowledge concerning the outcome on the one hand and the actual events on the other hand. We have been surprised at the number of persons who have not grasped this elementary principle.

Naturally, we do not claim to have the answers to all of the questions raised by the results obtained so far, and the rosearch with this special subject is continuing.

J. G. PRATT

Department of Psychiatry,

I. Stevenson

University of Virginia,

Charlottesville, Virginia.

Recejved Decembcr 30, 1968.

${ }^{1}$ Pratt, J. G., Stevenson, I., Roll, W. G., Blom, J. G., Meinsma, G. T., Keil, H. H. J., and Jacobson, N., Nature, 220, $89(1968)$

${ }^{2}$ Farge, E. J., Nature, 220, 412 (1968).

${ }^{3}$ Robertson, A., Nature, 220, 835 (1968). 